\title{
Effect of International Technology Transfer on the Technical Efficiency of High-Tech Manufacturing in China: A RAGA-PP-SFA Analysis
}

\author{
Shuzhen Zhou $\mathbb{D}^{1},{ }^{1}$ Qunzhao Deng $\mathbb{D},{ }^{1}$ and Feng Peng $\mathbb{D}^{2}$ \\ ${ }^{1}$ School of Management, Nanchang University, Nanchang 330031, China \\ ${ }^{2}$ School of Economics and Management, China Three Gorges University, Yichang 443002, China \\ Correspondence should be addressed to Shuzhen Zhou; zhoushuzhen@email.ncu.edu.cn and Feng Peng; pengfeng@ctgu.edu.cn
}

Received 2 January 2021; Revised 23 May 2021; Accepted 29 May 2021; Published 7 June 2021

Academic Editor: Alex Alexandridis

Copyright ( 92021 Shuzhen Zhou et al. This is an open access article distributed under the Creative Commons Attribution License, which permits unrestricted use, distribution, and reproduction in any medium, provided the original work is properly cited.

\begin{abstract}
The sustainable development of China's high-tech manufacturing (HTM) sector is restricted by dependence on technology introduction and foreign direct investment (FDI), low input-output efficiency, and environmental pollution. This study aimed to examine the roles of technology introduction and FDI in improving the technical efficiency of Chinese HTM from an environmental perspective. By integrating stochastic frontier analysis (SFA) and projection pursuit (PP) based on the real-coded accelerated genetic algorithm (RAGA), this study constructed a RAGA-PP-SFA model that considers undesirable outputs. This model includes various outputs, including environmental pollution, in the production function to improve estimation accuracy. Moreover, to verify the robustness of the estimation results, the results were provided when environmental pollutants were taken as input factors. The results showed that technology introduction could significantly promote HTM's technical efficiency, while FDI had no significant positive effect. By comparing the estimated results with those that did not consider environmental pollution, this study not only reveals different roles of technology introduction and FDI in improving HTM's technical efficiency but also confirms that ignoring environmental pollution will overestimate their roles (especially the role of FDI) in such improvement.
\end{abstract}

\section{Introduction}

In recent decades, China's high-tech manufacturing (HTM) industry has rapidly improved its technological capabilities, catching up with and even surpassing developed countries in certain technical fields and industries [1]. Technology introduction and foreign direct investment (FDI) have played important roles in the rapid development of HTM in China $[2,3]$; as a result, however, the HTM sector has become overreliant on foreign technology and investment [4]. Decades of extensive development have also led to low inputoutput efficiency and serious pollution in the HTM sector. These problems are intertwined and seriously restrict the sustainable development of HTM in China. In recent years, international competition in HTM has further intensified [5]. Moreover, many Chinese HTM enterprises, including
Huawei, have been added to the US trade blacklist called the "Entity List," further highlighting the sustainable development dilemmas these enterprises face $[6,7]$.

International technology transfer is a process in which developing countries acquire technology from abroad through technology introduction and FDI [8]. There are still many controversies in the research on the relationship between international technology transfer and technical efficiency in developing countries, including the three viewpoints summarized below.

The first view is that international technology transfer has a positive effect on technical efficiency. Some studies have shown that late-developing countries with weak R\&D capability and a lack of international experience can fill technical gaps by introducing foreign technology; they can also reinnovate on the basis of imported technology to 
achieve fairly rapid technological catch-up $[9,10]$. Technology introduction enables enterprises to identify and adopt higher-quality inputs or more effective production and management practices to strengthen their own capabilities [11], thus improving their technical efficiency. Developing countries can obtain more spillover effects through the introduction of high technology [12]. With regard to FDI, some studies have found that, in developing countries, enterprises funded by developed countries are usually more efficient than local ones, and competition from the former can improve the efficiency of the latter [13]. FDI can also produce externalities that will spread to host-country enterprises and improve their production efficiency [14]. FDI can promote the efficiency of host countries by transferring technology, exporting new products, developing large foreign markets, providing training for local labor, and improving technical and management skills [15]. In addition, if developing countries can adopt "green" FDI, it can not only promote economic growth, but it can also internalize the undesirable environmental externalities related to industrial production, thus having positive spillover effects for the domestic industries of host countries [16].

The second view suggests that international technology transfer negatively affects technology efficiency. Some studies have suggested that technology introduction can ensnare organizations in a "technology dependence trap" and suppress independent innovation ability [17, 18]. Technology introduction might also squeeze and replace the market space for local enterprises, inhibit the improvement of local enterprises' technological capabilities [19], and ultimately have a negative effect on the technical efficiency of developing countries. With regard to FDI, some studies have found that although foreign companies have stronger technological capabilities and better access to advanced technologies, they often confine their most advanced production and innovation activities to their home parent companies [20]. Further, foreign subsidiaries rely on direct technology transfer from their parent companies instead of increasing their own R\&D investment [21]. In addition, the potential environmental costs may offset the economic benefits brought by FDI since FDI may occur in tandem with the aggravation of pollution [22]. Therefore, FDI might not always have a positive effect on the technical efficiency of host countries.

The third view is that international technology transfer has an uncertain effect on technical efficiency; moreover, the effect is dependent upon the absorptive capacity of the recipient. Implicit technology is usually included in international technology transfer, and the recipient needs to have the corresponding absorption capacity to effectively utilize international technology transfer $[4,23]$. Absorptive capacity is closely related to R\&D stock and human capital. $\mathrm{R} \& \mathrm{D}$ can improve both technical ability and absorptive capacity; this can not only promote efficiency by generating new knowledge but can also improve the ability to learn and absorb external knowledge [24-26]. In addition to R\&D investment, human capital also plays an important role in absorbing international technology transfer $[27,28]$. Developing countries need a certain amount of human capital to benefit from international technology transfer [29].

A few studies have investigated the effect of either technology introduction or FDI on the technical efficiency of China's HTM industry [30, 31]. However, the relationship between them is rarely discussed from an environmental perspective, and there is a lack of a unified research framework that considers multiple technology sources [23, 32-34]. Some recent studies have found that domestic technology transfer and ownership structure might also have important effects on the technical efficiency of HTM. China's HTM enterprises can improve their efficiency through domestic technology transfer [35]. In the process of international technology transfer, the ownership structure is an important factor related to efficiency differences in Chinese enterprises [36, 37]. Accordingly, the technical efficiency of China's HTM sector is affected by varied and complex factors. When analyzing the relationship between international technology transfer and HTM's technical efficiency, to improve the accuracy of the estimation results, it is important to avoid the effects of measurement errors or random errors on the results. However, these factors are rarely taken into account in the existing literature.

In view of the above, this study attempted to incorporate international technology transfer, domestic technology transfer, R\&D investment, and other technology sources into the same analytical framework and reexamine the roles of technology transfer and FDI in improving the technical efficiency of China's HTM sector from an environmental perspective. A model was constructed that integrates stochastic frontier analysis (SFA) with projection pursuit (PP) based on the real-coded accelerated genetic algorithm (RAGA) (hereafter, RAGA-PP-SFA). This model puts various outputs, including environmental pollution, into the production function, thus improving the accuracy and robustness of the estimation results. This study also compared and analyzed the differences between estimation results with and without considering environmental pollution. This approach confirmed that the estimation results of previous studies were biased because of the neglect of environmental pollution.

\section{Methods and Data}

2.1. Methods. The technical efficiency of the HTM sector can usually be measured by data envelopment analysis (DEA) or SFA [38]. While DEA has advantages for the efficiency measurement of multiple outputs, it ignores the effects of random errors $[39,40]$. SFA distinguishes the influence of technical inefficiency and random errors and can analyze the factors influencing technical efficiency while also calculating technical efficiency [41-43]. This study used a stochastic frontier model to analyze the technical efficiency of China's HTM industry. However, since the traditional stochastic frontier model can only deal with a single output problem, this study integrated SFA with a PP model based on RAGA and constructed a RAGA-PP-SFA model considering undesirable outputs. Specifically, PP and RAGA were used to transform various outputs, including environmental 
pollution, into comprehensive output values; then, SFA was used to analyze the relationship between international technology transfer and HTM's technical efficiency. The proposed model incorporates various outputs, including environmental pollution, into the production function, which can not only overcome the defects of SFA (i.e., it can only deal with a single output problem) but can also avoid the effects of measurement errors or random errors on the estimation results, thus improving the accuracy of the results.

2.1.1. PP Model. The PP model is suitable for dealing with nonlinear and nonnormal high-dimensional data. By projecting high-dimensional data into low-dimensional space and analyzing the projection characteristics of low-dimensional space, the characteristics of high-dimensional data are studied [44, 45]. This method is superior to traditional multidimensional data-processing methods in terms of accuracy, robustness, and anti-interference. The specific steps of the PP model are presented as follows [46].

Step 1: calculate the projection value $z(i)$ of the comprehensive output:

$$
z(i)=\sum_{j=1}^{p} a(j) x(i, j),
$$

where $a(j)$ is the optimal projection direction formed by the projection of p-dimensional data $\{(x(i, j) \mid i=1,2, \ldots, n ; j=1,2, \ldots, p)\}$ into the lowdimensional subspace, and $x(i, j)$ is the result of the normalization processing of the sample index.

Step 2: construct the projection index function $Q(a)$ :

$$
Q(a)=S_{z} D_{z}
$$

where $S_{z}$ is the standard deviation of the projection value $z(i)$, and $D_{z}$ is the local density of the projection value $z(i)$; that is,

$$
\begin{aligned}
S_{z} & =\sqrt{\frac{\sum_{i=1}^{n}(z(i)-E(z))^{2}}{n-1}}, \\
D_{z} & =\sum_{i=1}^{n} \sum_{j=1}^{n}(R-r(i, j)) \times u(R-r(i, j)),
\end{aligned}
$$

where $E(z)$ is the average value of the projection values, $R$ is the window radius of local density, $r(i, j)$ is the distance between samples, $r(i, j)=|z(i)-z(j)|$, and $u(t)$ is a unit step function.

Step 3: optimize the projection index function $Q(a)$. For a certain index set, the projection index function $Q(a)$ only changes with the change in projection direction. The best projection direction can effectively reflect the characteristics of high-dimensional data, which can be estimated by solving the maximization problem of the projection index function. The maximized objective function is as follows:

$$
\left\{\begin{array}{l}
\max Q(a)=S_{z} D_{z} \\
\text { s.t. } \sum_{j=1}^{p} a^{2}(j)=1 .
\end{array}\right.
$$

Step 4: calculate the comprehensive output value. After substituting the best projection direction $a^{*}$ obtained in Step 3 into formula (1), the projection value $z^{*}(i)$ of each sample can be obtained (i.e., the comprehensive output value).

2.1.2. RAGA. The genetic algorithm (GA) is normally used to solve the optimal projection direction, but because the simple genetic algorithm (SGA) is prone to premature convergence, RAGA was used to enhance optimization performance and better obtain the optimal solution [47].

Let the optimization problem be a minimization objective function:

$$
\left\{\begin{array}{l}
\min g(x(1), x(2), \ldots, x(p)) \\
a(j) \leq x(j) \leq b(j)
\end{array}\right.
$$

where $g$ is the objective function, $x(j)$ is the $j$ th optimized variable, $[a(j), b(j)]$ is the variation interval of $x(j)$, and $p$ is the number of optimized variables. The modeling process of RAGA [47] is presented as follows:

Step 1: encoding. Using the following linear transformation,

$$
x(j)=a(j)+y(j)[b(j)-a(j)],
$$

match $x(j)$ to the real number $y(j)$ over the interval $[0,1]$.

Step 2: initialize the parent group. $y(j, i)$ is brought into formula (6) to obtain the optimized variable value $x(j, i)$. The corresponding objective function values $g(i)$ are sorted from small to large, and the top individuals are defined as excellent individuals.

Step 3: evaluate the fitness of the parent group. Define the fitness function value of the $i$ th parent individuals after sorting, as follows:

$$
G(i)=\frac{1}{g(i) \times g(i)+0.001} .
$$

Step 4: selection operation is performed to generate the first offspring group $\left\{y_{1}(j, i) \mid j=1 \sim p, i=1 \sim n\right\}$. Let the selection probability $p_{s}(i)$ of the parent individual $y(j, i)$ be

$$
p_{s}(i)=\frac{G(i)}{\sum_{i=1}^{n} G(i)} \text {. }
$$

Step 5: perform the hybridization operation to generate a second offspring group $\left\{y_{2}(j, i) \mid j=1 \sim p, i=1 \sim n\right\}$. According to the selection probability of formula (8), parent individuals $y\left(j, i_{1}\right)$ and $y\left(j, i_{2}\right)$ are randomly selected as parents for the following linear transformation to produce an offspring individual $y_{2}(j, i)$ : 


$$
\left\{\begin{array}{l}
y_{2}(j, i)=u_{1} y\left(j, i_{1}\right)+\left(1-u_{1}\right) y\left(j, i_{2}\right), u_{3}<0.5, \\
y_{2}(j, i)=u_{2} y\left(j, i_{1}\right)+\left(1-u_{2}\right) y\left(j, i_{2}\right), u_{3} \geq 0.5
\end{array}\right.
$$

where $u_{1}, u_{2}$, and $u_{3}$ are all random numbers.

Step 6: perform the mutation operation to generate a third offspring group $\left\{y_{3}(j, i) \mid j=1 \sim p, i=1 \sim n\right\}$. $p$ random numbers are used to replace individual $y(j, i)$ with the probability of $p_{m}(i)=1-p_{s}(i)$; that is,

$$
\left\{\begin{array}{l}
y_{3}(j, i)=u(j), u_{m}<p_{m}(i), \\
y_{3}(j, i)=y(j, i), u_{m} \geq p_{m}(i),
\end{array}\right.
$$

where $u(j)$ and $u_{m}$ are all random numbers.

Step 7: evolutionary iteration. The parent group is evaluated, selected, hybridized, mutated, and so on.

Step 8: accelerated circulation. When the objective function value of the best individual is less than a certain set value, or the algorithm runs for a predetermined acceleration cycle time, the average value of the best individual or excellent individual in the current group is taken as the result of RAGA.

2.1.3. RAGA-PP-SFA Model. Following Battese and Coelli [48], the production frontier of the RAGA-PP-SFA model is set in the Cobb-Douglas function form; that is,

$$
\ln C Y_{i t}=\beta_{0}+\beta_{1} \ln K_{i t}+\beta_{2} \ln L_{i t}+\left(V_{i t}-U_{i t}\right),
$$

where $C Y_{i t}$ is the comprehensive output value of production unit $i$ at time $t$, which is obtained based on the RAGA-PP model. $K_{i t}$ and $L_{i t}$ denote the capital input and labor input, respectively, of production unit $i$ at time $t . \beta_{0}, \beta_{1}$, and $\beta_{2}$ are parameters to be estimated. $V_{i t}$ is the random error and follows the normal distribution $N\left(0, \sigma_{V}^{2}\right) . U_{i t}$ is an independent nonnegative random variable with the same distribution, which is used to explain technical inefficiency and obeys normal distribution $N\left(z_{i t} \delta, \sigma_{U}^{2}\right)$, where $z_{i t}$ is the vector affecting technical efficiency. $\delta$ is the unknown parameter vector.

The RAGA-PP-SFA model can also be set in the form of a trans-log production function:

$$
\begin{aligned}
\ln C Y_{i t}= & \beta_{0}+\beta_{1} \ln K_{i t}+\beta_{2} \ln L_{i t}+\beta_{3}\left(\ln K_{i t}\right)^{2} \\
& +\beta_{4}\left(\ln L_{i t}\right)^{2}+\beta_{5} \ln K_{i t} \ln L_{i t}+\left(V_{i t}-U_{i t}\right) .
\end{aligned}
$$

In addition, the time change trend term can also be introduced into the production function to examine the effect of technological progress. The function form is as follows:

$$
\ln Y_{i t}=\beta_{0}+\eta t+\beta_{1} \ln K_{i t}+\beta_{2} \ln L_{i t}+\left(V_{i t}-U_{i t}\right),
$$

where $\beta_{0}, \beta_{1}$, and $\beta_{2}$ are as defined earlier and $\eta$ is the time variation coefficient.

The most suitable form of the stochastic frontier production function is determined by the likelihood ratio test
(LR test) to examine the influence of international technology transfer on the technical efficiency of the HTM sector.

The technical inefficiency function of the RAGA-PP-SFA model can be set as

$$
m_{i t}=\delta_{0}+\delta_{1} \mathrm{TI}_{i t}+\delta_{2} \mathrm{FDI}_{i t}+\omega \Phi,
$$

where $\mathrm{TI}_{i t}$ and $\mathrm{FDI}_{i t}$ represent two kinds of international technology transfer: technology introduction and FDI, respectively. $\Phi$ is the control vector, $\omega$ is the parameter vector, and $\delta_{i}(i=0,1,2)$ is the estimated coefficient of the corresponding variable.

If $\delta_{i}$ is positive, it means the corresponding variable is positively correlated with technical inefficiency; that is, it has a negative effect on technical efficiency.

In addition to technology introduction (TI) and foreign direct investment (FDI), R\&D investment (RD), human capital (HC), domestic technology transfer (DT), and ownership structure (OS) might also be important factors influencing technical inefficiency (technical efficiency); these are regarded as control variables. Thus, we have

$$
\omega \Phi=\omega_{1} \mathrm{RD}_{i t}+\omega_{2} \mathrm{HC}_{i t}+\omega_{3} \mathrm{DT}_{i t}+\omega_{4} \mathrm{OS}_{i t} .
$$

To judge whether the RAGA-PP-SFA model setting is reasonable, the variance parameter $\gamma$ needs to be tested, where

$$
\gamma=\frac{\sigma_{U}^{2}}{\left(\sigma_{U}^{2}+\sigma_{V}^{2}\right)} .
$$

If $\gamma$ is significantly different from 0 , it means there is a technical inefficiency effect in the production function. The closer $\gamma$ is to 1 , the more deviation produced by technical inefficiency; thus, the RAGA-PP-SFA model is more suitable.

2.2. Data. Technical efficiency is often used to measure the ability of an organization to obtain maximum output under a given input [11]. It involves many aspects, such as production, innovation, and environment $[49,50]$. At the same time, considering data availability, this study selected three output indicators for the HTM industry, including main business revenue $(Y)$, sales revenue of new products (YNP), and sulfur dioxide emissions $\left(\mathrm{SO}_{2}\right)$ [51]. These were converted into one-dimensional variables to measure the comprehensive output value (CY) of the HTM sector. Labor input $(L)$ was measured by the average number of employees in HTM enterprises in various provinces, and physical capital $(K)$ was calculated using the perpetual inventory method (PIM) [52].

For TI, the knowledge stock can be calculated using the perpetual inventory method; RD and DT can be calculated using the same method for measuring TI [53]. FDI is expressed by the proportion of foreign capital in the paid-in capital of the industry [54].

Human capital is usually estimated by years of education. However, because it is impossible to obtain data for years of education among HTM employees in China's 
various provinces, this study used the ratio of R\&D personnel to employed persons to express HC [55]. OS is expressed by the proportion of the total output value of nonstate-owned enterprises [23].

The data came from the China High-Tech Industry Statistics Yearbook, China Industrial Statistics Yearbook, and China Environmental Statistics Yearbook. This study selected relevant statistical data for 28 Chinese provinces (data of other provinces are missing) from 2005 to 2016 to analyze the effect of international technology transfer on HTM's technical efficiency. Table 1 shows the descriptive statistical results of the variables.

\section{Results and Discussion}

3.1. Measurement Results for Comprehensive Output. The best projection direction vector of the output variables of China's HTM industry was calculated using the RAGA-PP model:

$$
a^{*}=(0.793,0.609,0.009)
$$

After the best projection direction vector was brought into formula (1), the comprehensive output value of China's interprovincial HTM sector from 2005 to 2016 was obtained (Table 2).

\subsection{Estimation Results considering Environmental Pollution.} To analyze the relationship between international technology transfer and HTM's technical efficiency, it is necessary to determine whether RAGA-PP-SFA is applicable and select the appropriate production function form. According to the logarithmic likelihood function values of formulas (12)-(14), LR test values corresponding to various hypothesis tests were calculated. The test results showed that the trans-log production function was not applicable to the sample data, and it was unnecessary to consider technological progress in the production function. For this study, the Cobb-Douglas production function was selected to examine the effect of international technology transfer on the technical efficiency of HTM in China. Table 3 shows the estimation results of the stochastic frontier production function and inefficiency function obtained by the RAGA-PP-SFA model.

Model 1.1 takes RD and HC as control variables, and model 1.2 adds DT and OS as control variables. The variance parameters of model 1.1 and model 1.2 are both significant at the $1 \%$ significance level, and their values are both higher than 0.600 . This indicates that the deviation between the actual output and the theoretical maximum output mainly came from the technical invalid effect. Therefore, the model setting of RAGA-PP-SFA was reasonable.

Comparing models 1.1 and 1.2 , we can see that the estimation results of the two models are basically consistent. Among the factors influencing technical inefficiency, both models indicated that the coefficient of TI was significantly negative. The coefficient of FDI was negative but not statistically significant. This indicates that TI significantly promoted HTM's technical efficiency while FDI did not. The coefficient estimates of RD and $\mathrm{HC}$ were also significantly negative, indicating that $\mathrm{RD}$ and $\mathrm{HC}$ could also significantly promote the technical efficiency of HTM.

Model 1.2 also shows that DT had a positive effect on inefficiency in China's HTM sector, but it was not statistically significant. The coefficient of OS was significantly negative, indicating that increasing the proportion of nonstate-owned enterprises can improve HTM's technical efficiency. Since RD, HC, and OS all had a significant influence on HTM's technical efficiency, model 1.2 analyzed the effect of international technology transfer on HTM's technical efficiency under the condition of controlling these factors at the same time. Thus, the estimated result was more accurate than that of model 1.1.

3.3. Technical Efficiency of High-Tech Manufacturing considering Environmental Pollution. Based on model 1.2, the technical efficiency of China's interprovincial HTM industry was calculated with consideration of pollution. Table 4 shows the average values for HTM's technical efficiency in each province from 2005 to 2016.

Eastern Region includes Beijing, Fujian, Guangdong, Hainan, Hebei, Jiangsu, Liaoning, Shandong, Shanghai, Tianjin, and Zhejiang. Middle Region includes Anhui, Heilongjiang, Henan, Hubei, Hunan, Jiangxi, Jilin, and Shanxi. Western Region includes Chongqing, Gansu, Guangxi, Guizhou, Inner Mongolia, Ningxia, Shaanxi, Sichuan, and Yunnan.

Table 4 shows that from 2005 to 2016, HTM's technical efficiency was low, with an annual average of only 0.423 . HTM's technical efficiency varied greatly among provinces. The province with the highest technical efficiency was Shanghai, with an average value of 0.936 . The province with the lowest technical efficiency was Shaanxi, with an average of 0.178 .

Dividing these provinces into the eastern, central, and western regions, we can see that the provinces with low technical efficiency are concentrated in the central and western regions. The average technical efficiency of the eastern region was 0.657 , that of the central region was 0.265 , and that of the western region was 0.278 . The value for the eastern region was much higher than that of the central and western regions. Figure 1 shows the regional differences in the technical efficiency of HTM in China.

In Figure 1, HTM's technical efficiency shows an increasing trend from 2005 to 2016, with only a brief decline in 2010. This could be related to the fact that China implemented the Circular Economy Promotion Law in 2009, which established stricter control standards for pollutant emissions by manufacturing enterprises. Companies had to implement environmental protection technologies in a short period of time, which increased costs and resulted in a brief decline in technical efficiency. From 2005 to 2016, the technical efficiency of HTM in the eastern, central, and western regions also showed an increasing trend. After 2010, the technical efficiency of HTM in the central region grew faster than that in the eastern and western regions. The reason could be that the 2009 Plan for Promoting the Rise of the Central Region significantly accelerated the development of the region's HTM sector. 
TABLE 1: Descriptive statistical results of the variables.

\begin{tabular}{|c|c|c|c|c|c|}
\hline Variable & Unit & Mean & Std. dev. & Min & Max \\
\hline Main business revenue $(Y)$ & Billion yuan & 273.366 & 528.359 & 1.103 & 3820.241 \\
\hline Sales revenue of new products (YNP) & Billion yuan & 73.080 & 170.616 & 0.002 & 1572.278 \\
\hline Sulfur dioxide emissions $\left(\mathrm{SO}_{2}\right)$ & Kiloton & 3.807 & 3.262 & 0.308 & 17.793 \\
\hline Physical capital $(K)$ & Billion yuan & 105.347 & 136.793 & 2.007 & 1105.398 \\
\hline Labor input $(L)$ & Thousand people & 385.683 & 703.018 & 4.739 & 3894.169 \\
\hline Technology introduction (TI) & Billion yuan & 1.563 & 2.670 & 0.005 & 14.090 \\
\hline Foreign direct investment (FDI) & Ratio & 0.173 & 0.145 & 0.000 & 0.588 \\
\hline $\mathrm{R} \& \mathrm{D}$ investment (RD) & Billion yuan & 11.216 & 25.335 & 0.009 & 235.423 \\
\hline Human capital (HC) & Ratio & 0.044 & 0.026 & 0.002 & 0.193 \\
\hline Domestic technology transfer (DT) & Billion yuan & 0.243 & 0.388 & 0.003 & 3.963 \\
\hline Ownership structure (OS) & Ratio & 0.778 & 0.176 & 0.180 & 0.998 \\
\hline
\end{tabular}

TABLE 2: Comprehensive output value of China's interprovincial high-tech manufacturing industry considering environmental pollution.

\begin{tabular}{|c|c|c|c|c|c|c|c|c|c|c|c|c|}
\hline Area & 2005 & 2006 & 2007 & 2008 & 2009 & 2010 & 2011 & 2012 & 2013 & 2014 & 2015 & 2016 \\
\hline Beijing & 0.067 & 0.083 & 0.137 & 0.123 & 0.131 & 0.130 & 0.132 & 0.133 & 0.152 & 0.171 & 0.162 & 0.179 \\
\hline Tianjin & 0.084 & 0.095 & 0.087 & 0.078 & 0.081 & 0.087 & 0.091 & 0.124 & 0.168 & 0.178 & 0.189 & 0.174 \\
\hline Hebei & 0.013 & 0.013 & 0.015 & 0.016 & 0.018 & 0.021 & 0.022 & 0.027 & 0.031 & 0.036 & 0.045 & 0.048 \\
\hline Shanxi & 0.006 & 0.007 & 0.008 & 0.008 & 0.008 & 0.009 & 0.008 & 0.012 & 0.013 & 0.015 & 0.017 & 0.018 \\
\hline Inner Mongolia & 0.006 & 0.007 & 0.008 & 0.008 & 0.010 & 0.009 & 0.010 & 0.009 & 0.010 & 0.010 & 0.012 & 0.013 \\
\hline Liaoning & 0.023 & 0.024 & 0.029 & 0.032 & 0.033 & 0.040 & 0.044 & 0.048 & 0.051 & 0.051 & 0.046 & 0.042 \\
\hline Jilin & 0.011 & 0.012 & 0.013 & 0.015 & 0.018 & 0.020 & 0.024 & 0.029 & 0.035 & 0.039 & 0.043 & 0.050 \\
\hline Heilongjiang & 0.015 & 0.011 & 0.012 & 0.012 & 0.013 & 0.013 & 0.013 & 0.014 & 0.015 & 0.015 & 0.016 & 0.015 \\
\hline Shanghai & 0.141 & 0.163 & 0.180 & 0.190 & 0.181 & 0.200 & 0.189 & 0.186 & 0.183 & 0.195 & 0.210 & 0.213 \\
\hline Jiangsu & 0.145 & 0.177 & 0.230 & 0.294 & 0.328 & 0.370 & 0.472 & 0.574 & 0.629 & 0.689 & 0.795 & 0.894 \\
\hline Zhejiang & 0.054 & 0.070 & 0.078 & 0.073 & 0.082 & 0.092 & 0.107 & 0.123 & 0.148 & 0.166 & 0.204 & 0.236 \\
\hline Anhui & 0.012 & 0.013 & 0.014 & 0.014 & 0.018 & 0.020 & 0.030 & 0.040 & 0.047 & 0.062 & 0.084 & 0.101 \\
\hline Fujian & 0.062 & 0.068 & 0.072 & 0.078 & 0.075 & 0.093 & 0.109 & 0.119 & 0.128 & 0.130 & 0.143 & 0.169 \\
\hline Jiangxi & 0.012 & 0.014 & 0.015 & 0.016 & 0.021 & 0.024 & 0.027 & 0.034 & 0.042 & 0.047 & 0.062 & 0.075 \\
\hline Shandong & 0.054 & 0.065 & 0.085 & 0.096 & 0.118 & 0.124 & 0.143 & 0.177 & 0.200 & 0.227 & 0.284 & 0.308 \\
\hline Henan & 0.014 & 0.016 & 0.018 & 0.019 & 0.024 & 0.027 & 0.036 & 0.052 & 0.110 & 0.135 & 0.173 & 0.185 \\
\hline Hubei & 0.015 & 0.019 & 0.021 & 0.024 & 0.033 & 0.037 & 0.041 & 0.052 & 0.062 & 0.074 & 0.092 & 0.102 \\
\hline Hunan & 0.012 & 0.012 & 0.013 & 0.016 & 0.021 & 0.025 & 0.035 & 0.043 & 0.063 & 0.070 & 0.087 & 0.098 \\
\hline Guangdong & 0.299 & 0.359 & 0.387 & 0.444 & 0.500 & 0.665 & 0.734 & 0.817 & 0.930 & 1.031 & 1.184 & 1.411 \\
\hline Guangxi & 0.008 & 0.008 & 0.009 & 0.009 & 0.010 & 0.012 & 0.015 & 0.019 & 0.024 & 0.027 & 0.033 & 0.038 \\
\hline Hainan & 0.009 & 0.009 & 0.009 & 0.009 & 0.010 & 0.010 & 0.010 & 0.011 & 0.011 & 0.011 & 0.012 & 0.012 \\
\hline Chongqing & 0.011 & 0.011 & 0.012 & 0.015 & 0.018 & 0.021 & 0.039 & 0.047 & 0.059 & 0.086 & 0.130 & 0.141 \\
\hline Sichuan & 0.026 & 0.030 & 0.038 & 0.041 & 0.052 & 0.046 & 0.073 & 0.086 & 0.110 & 0.124 & 0.123 & 0.140 \\
\hline Guizhou & 0.004 & 0.004 & 0.005 & 0.006 & 0.007 & 0.008 & 0.008 & 0.009 & 0.010 & 0.014 & 0.018 & 0.021 \\
\hline Yunnan & 0.008 & 0.009 & 0.009 & 0.009 & 0.010 & 0.010 & 0.010 & 0.011 & 0.012 & 0.013 & 0.014 & 0.014 \\
\hline Shaanxi & 0.016 & 0.017 & 0.019 & 0.019 & 0.019 & 0.022 & 0.023 & 0.026 & 0.028 & 0.034 & 0.042 & 0.053 \\
\hline Gansu & 0.006 & 0.007 & 0.007 & 0.007 & 0.007 & 0.007 & 0.006 & 0.007 & 0.007 & 0.007 & 0.007 & 0.009 \\
\hline Ningxia & 0.003 & 0.003 & 0.003 & 0.004 & 0.005 & 0.005 & 0.003 & 0.002 & 0.003 & 0.003 & 0.004 & 0.004 \\
\hline
\end{tabular}

For a long time, HTM in the eastern region has greatly differed from that in the central and western region in terms of technology introduction, FDI, R\&D investment, human capital, and other aspects. As a result, the technical efficiency of HTM in East China has been much higher than that in Central and Western China. At present, the technical efficiency of HTM remains generally low; it is urgent, therefore, to aim for rapid growth through technology introduction, increasing $\mathrm{R} \& \mathrm{D}$ investment, and other means.

3.4. Robustness Test. When analyzing technical efficiency, environmental pollution can be regarded as an undesirable output [56]. It can also be used as an input factor to introduce the production function along with capital and labor input $[57,58]$. To test whether the estimation results for the relationship between international technology transfer and HTM's technical efficiency by these two methods were consistent, estimation results are also provided with pollutants taken as input factors. This serves to verify the robustness of the results. Table 5 shows the robustness test results.

The LR test results showed that the trans-log production function was not applicable to the sample data, and it was unnecessary to consider technological progress in the production function. Therefore, the Cobb-Douglas production function was selected for use with the RAGA-PPSFA model to analyze the effect of international technology 
TABLE 3: Estimation results when considering environmental pollution.

\begin{tabular}{lcc}
\hline Variables & Model 1.1 & Model 1.2 \\
\hline Technical inefficiency function & & $2.392^{* * *}(13.513)$ \\
Constant & $1.536^{* * *}(15.939)$ & $-0.254^{* * *}(-8.765)$ \\
TI & $-0.298^{* * *}(-11.632)$ & $-0.345(-1.035)$ \\
FDI & $-0.452(-1.153)$ & $-0.012^{* * *}(-3.817)$ \\
RD & $-0.008^{* * *}(-2.906)$ & $-3.641^{* * *}(-3.912)$ \\
HC & $-2.071^{* *}(-2.301)$ & $0.230(1.359)$ \\
DT & & $-1.102^{* * *}(-6.456)$ \\
OS & & $0.150^{* * *}(11.602)$ \\
Model diagnostics & & $0.683^{* * *}(13.840)$ \\
$\sigma 2$ & $0.175^{* * *}(8.961)$ & 277.496 \\
$\gamma$ & $0.701^{* * *}(14.839)$ & -123.220 \\
LR test & 209.986 & 336 \\
Log likelihood & -156.975 & 336 \\
Number of samples & & -120 \\
\hline
\end{tabular}

Values in parentheses are the corresponding $t$-statistics. ${ }^{*},{ }^{* *}$, and ${ }^{* * *}$ indicate significance levels of $10 \%, 5 \%$, and $1 \%$, respectively.

TABLE 4: Average values for the technical efficiency of high-tech manufacturing in China, 2005-2016.

\begin{tabular}{lccc}
\hline Area & Technical efficiency & Area & Technical efficiency \\
\hline Beijing & 0.827 & Hubei & 0.315 \\
Tianjin & 0.887 & Hunan & 0.328 \\
Hebei & 0.236 & Guangdong & 0.928 \\
Shanxi & 0.178 & Guangxi & 0.246 \\
Inner Mongolia & 0.275 & Hainan & 0.500 \\
Liaoning & 0.317 & Chongqing & 0.365 \\
Jilin & 0.265 & Sichuan & 0.358 \\
Heilongjiang & 0.219 & Guizhou & 0.197 \\
Shanghai & 0.936 & Yunnan & 0.305 \\
Jiangsu & 0.862 & Shaanxi & 0.230 \\
Zhejiang & 0.510 & Gansu & 0.234 \\
Anhui & 0.290 & Ningxia & 0.294 \\
Fujian & 0.695 & Eastern Region & 0.657 \\
Jiangxi & 0.230 & Middle Region & 0.265 \\
Shandong & 0.529 & Western Region & 0.278 \\
Henan & 0.295 & Overall & 0.423 \\
\hline
\end{tabular}

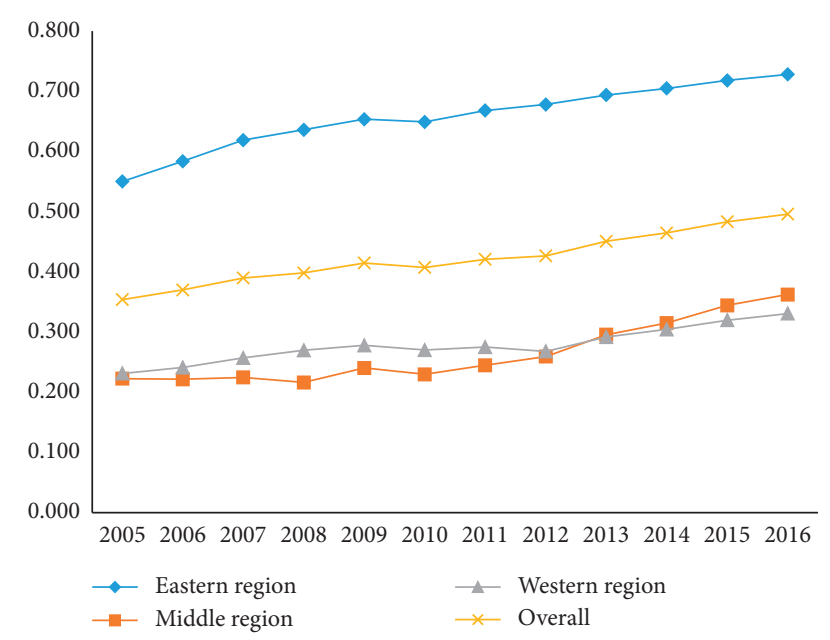

FIGURE 1: Regional differences in the technical efficiency of China's high-tech manufacturing sector. transfer on HTM's technical efficiency. The variance parameters of models 2.1 and 2.2 were significant at the $1 \%$ significance level, and their values were higher than 0.600 . Thus, the setting of the RAGA-PP-SFA model was reasonable.

Models 2.1 and 2.2 both showed that TI significantly improved HTM's technical efficiency while FDI did not. Both RD and HC could significantly promote the technical efficiency of HTM. Model 2.2 also showed that while the influence of DT on HTM's technical efficiency was not significant, OS could significantly promote it.

Therefore, the two estimation results-which took environmental pollution as an input factor and as an undesirable output-were highly consistent in direction and significance, with only slight changes in numerical value. Both showed that TI could significantly promote HTM's technical efficiency while FDI had no significant effect. Under the condition of controlling $\mathrm{RD}, \mathrm{HC}$, 
TABLE 5: Robustness test results.

\begin{tabular}{lcc}
\hline Variables & Model 2.1 & Model 2.2 \\
\hline Technical & & \\
inefficiency & & \\
function & & \\
Constant & $1.341^{* * *}(11.550)$ & $2.264^{* * *}(13.340)$ \\
TI & $-0.287^{* * *}(-9.154)$ & $-0.235^{* * *}(-7.905)$ \\
FDI & $-0.026(-0.082)$ & $-0.096(-0.331)$ \\
RD & $-0.007^{* * *}(-6.968)$ & $-0.010^{* * *}(-3.056)$ \\
HC & $-4.953^{* * *}(-4.801)$ & $-7.672^{* * *}(-7.108)$ \\
DT & & $0.106(0.594)$ \\
OS & & $-1.009^{* * *}(-6.227)$ \\
\hline Model & & \\
diagnostics & & $0.166^{* * *}(12.296)$ \\
$\sigma 2$ & $0.187^{* * *}(10.134)$ & $0.689^{* * *}(12.212)$ \\
$\gamma$ & $0.654^{* * *}(7.626)$ & 188.554 \\
LR test & 151.899 & -140.681 \\
Log likelihood & -159.008 & 336 \\
Number of & 336 & \\
samples & & \\
\hline
\end{tabular}

Values in parentheses are the corresponding $t$-statistics. ${ }^{*},{ }^{* *}$, and ${ }^{* * *}$ indicate significance levels of $10 \%, 5 \%$, and $1 \%$, respectively.

DT, and OS, the knowledge stock of TI increased by one billion yuan, the former showed that HTM's technical efficiency would increase by 0.254 , while the latter showed that it would increase by 0.235 . This indicates that the RAGA-PP-SFA model was able to obtain consistent estimation results, whether changing the production function or the technical inefficiency function. Therefore, this study's estimated results can be considered robust.

3.5. Estimation Results without considering Environmental Pollution. To compare the results when considering environmental pollution and not considering environmental pollution, this study also used RAGA-PP-SFA to analyze the effect of international technology transfer on HTM's technical efficiency without considering environmental pollution. Table 6 shows the results.

The LR test results showed that when environmental pollution was not considered, the transcendental logarithmic production function was not applicable to the sample data, and there was no need to consider technological progress in the production function. Thus, the CobbDouglas production function was selected for use with RAGA-PP-SFA to analyze the effect of international technology transfer on HTM's technical efficiency. The variance parameters of models 3.1 and 3.2 were both significant at the level of $1 \%$, and their values were both higher than 0.600 . This indicates that the setting of the RAGA-PP-SFA model was reasonable.

Models 3.1 and 3.2 both showed that TI and FDI significantly promoted the technical efficiency of HTM; RD and HC could significantly promote it as well. Model 3.2 showed, moreover, that the influence of DT on HTM's technical efficiency was not significant while OS did play a significant role in technical efficiency.
TABLE 6: Estimation results without considering environmental pollution.

\begin{tabular}{lcc}
\hline Variables & Model 3.1 & Model 3.2 \\
\hline Technical & & \\
inefficiency & & \\
function & & \\
Constant & $1.810^{* * *}(16.486)$ & $2.791^{* * *}(15.449)$ \\
TI & $-0.300^{* * *}(-10.849)$ & $-0.282^{* * *}(-12.271)$ \\
FDI & $-0.645^{*}(-1.739)$ & $-0.843^{* * *}(-2.871)$ \\
RD & $-0.010^{* * *}(-5.556)$ & $-0.009^{* * *}(-2.779)$ \\
HC & $-4.359^{* * *}(-5.866)$ & $-7.794^{* * *}(-6.672)$ \\
DT & & $0.046(0.252)$ \\
OS & & $-1.169^{* * *}(-6.147)$ \\
\hline Model diagnostics & & \\
$\sigma 2$ & $0.225^{* * *}(10.601)$ & $0.208^{* * *}(14.323)$ \\
$\gamma$ & $0.667^{* * *}(8.234)$ & $0.612^{* * *}(7.300)$ \\
LR test & 188.045 & 237.044 \\
Log likelihood & -200.683 & -176.184 \\
Number of samples & 336 & 336 \\
\hline
\end{tabular}

Values in parentheses are the corresponding $t$-statistics. ${ }^{*},{ }^{* *}$, and ${ }^{* * * * * *}$ indicate significance levels of $10 \%, 5 \%$, and $1 \%$, respectively.

Comparing models 1.2 and 3.2, we find significant differences between the two estimation results when considering environmental pollution and when not considering it. Considering environmental pollution, if the knowledge stock of TI increases by one billion yuan, HTM's technical efficiency will increase by 0.254 . FDI, meanwhile, had no significant effect on HTM's technical efficiency. Without considering environmental pollution, if the knowledge stock of TI increases by one billion yuan, HTM's technical efficiency will increase by 0.282 ; then, FDI can significantly promote HTM's technical efficiency. If FDI increases by one percentage point, HTM's technical efficiency will increase by 0.843 percentage points.

Therefore, ignoring environmental pollution will overestimate the role of TI and, especially, the role of FDI in improving HTM's technical efficiency.

3.6. Discussion. Whether considering environmental pollution or not, the two estimation results showed that TI significantly promoted HTM's technical efficiency. The reason is that China's HTM sector is integrated into the global value chain, and domestic enterprises can identify and introduce suitable technologies that meet environmental requirements. China has also continuously improved its industrial technology policies and taken active measures to promote technology introduction, digestion, and absorption. For example, the 2006 Catalogue of Technology Encouragement in China created preferential tax policies for imported technologies that meet the requirements and encouraged enterprises to increase funding for technology introduction, digestion, and absorption, producing an upsurge in foreign technology introduction [59]. With the support of such policies and measures, Chinese enterprises have not only improved their ability to digest and absorb foreign technologies but also paid more attention to obtaining technology licenses, consulting, and services [60]. 
Therefore, China's HTM sector has improved its technical efficiency by digesting and absorbing imported technology.

When environmental pollution was not considered, it was found that FDI could significantly promote HTM's technical efficiency; when environmental pollution was considered, the effect was no longer significant. This shows that, on the one hand, foreign-funded high-tech enterprises have strong technical and management advantages, and there are positive technology spillover effects on HTM in China. On the other hand, in some areas of China, environmental standards are relatively low, and FDI can also bring environmental pollution to a certain extent. To save costs, foreign-funded enterprises do not always adopt clean production technologies but only aim to meet local environmental protection standards by treating the pollutants they discharge. Environmental costs offset the technology spillover effect brought by FDI [22]. Therefore, after considering the pollution, FDI does not significantly promote the technical efficiency of HTM.

As for the control variables, whether considering environmental pollution or not, $\mathrm{RD}, \mathrm{HC}$, and $\mathrm{OS}$ all had significantly positive effects on HTM's technical efficiency. This was consistent with theoretical expectations. Improving RD and $\mathrm{HC}$ enhances the ability to absorb foreign technology and can help Chinese HTM enterprises improve technical efficiency in the process of introducing, absorbing, and reinnovating technology. The analysis of the relationship between OS and HTM's technical efficiency indicated that appropriately increasing the proportion of non-state-owned enterprises can also improve the technical efficiency of HTM in China.

Contrary to theoretical expectation, however, DT had no significant promoting effect on HTM. The reason is that domestic technologies are usually mature technologies that are not at the forefront of technology development and have a little spillover effect on domestic enterprises [4]; they cannot, therefore, promote HTM's technical efficiency.

\section{Conclusions}

This study examined the different roles of technology introduction and FDI in improving HTM's technical efficiency from an environmental perspective. When considering environmental pollution, it was found that technology introduction played a significant role in promoting HTM's technical efficiency while FDI had no significant positive effect. When not considering environmental pollution, technology introduction and FDI both significantly promoted HTM's technical efficiency. This study not only reveals the difference between technology introduction and FDI in improving HTM's technical efficiency but also confirms that ignoring environmental pollution will result in overestimating the effect of technology introduction and especially FDI on improving HTM's technical efficiency.

4.1. Theoretical Contribution. Different from previous work, this study considered undesirable outputs when analyzing HTM's technical efficiency. It also incorporated various technology sources (e.g., international technology transfer, domestic technology transfer, and R\&D investment) into the same analysis framework and used RAGA-PP-SFA to investigate the effect of international technology transfer on HTM's technical efficiency. This model can not only avoid the effect of measurement errors or random errors but also overcome the limitation of SFA in that it can only deal with -+a single output problem [61, 62].

In addition, when setting the SFA production function, this study adopted two ideas, one of which regarded environmental pollution as an undesired output [56]. The other idea took environmental pollution as an input factor and introduced the production function along with capital and labor inputs [57, 58]. These two ideas demonstrated the robustness of the estimation results from different angles.

Finally, this study examined the differences between the estimation results when considering environmental pollution and when not considering environmental pollution. It was confirmed that not considering environmental pollution, as in some previous studies, produced biased estimation results.

4.2. Implications for Practice. In addition to offering new insights into the roles of technology introduction and FDI in improving HTM's technical efficiency, this study provides a scientific basis for China to formulate technology transfer policies and promote HTM's sustainable development.

Overall, the technical efficiency of China's HTM sector is currently low, and technology introduction still plays an important role in improving technical efficiency. While encouraging Chinese HTM firms to introduce suitable foreign technologies that meet environmental requirements, a selection mechanism for technology introduction should also be established to reduce dependence on a single technology introduction path.

China's HTM industry should absorb FDI while also increasing the intensity of technology introduction. To give full play to the positive effects of FDI on HTM's technical efficiency, it is necessary to further improve FDI policies and regulations, attract high-quality foreign-funded enterprises that meet environmental requirements, and create a good environment for those enterprises to cooperate in $\mathrm{R} \& \mathrm{D}$ in China.

That said, relying on international technology transfer is not the best way for emerging economies to catch up, nor is it a sustainable model for developing countries to fill the technology gap. While taking advantage of international technology transfer, China's HTM industry should also pay attention to improving their own R\&D capabilities, improving the digestion and absorption of foreign technologies, reducing excessive dependence on international technology transfer, and improving the core technical capabilities of HTM in China.

4.3. Limitations and Future Research. This study has some limitations. When analyzing HTM's technical efficiency, undesirable outputs such as environmental pollution were considered. In this regard, the selection of environmental 
pollution indicators should include solid waste, waste gas, and wastewater. However, limited by data availability, this study only chose sulfur dioxide emissions as the environmental pollution indicator and did not consider other factors, such as solid waste and wastewater.

In addition, the HTM sector in China includes the pharmaceutical and aerospace manufacturing industries, among others. These industries have different technical bases and are different in terms of dependence on foreign technology and foreign capital. Therefore, the effect of international technology transfer on technical efficiency in different HTM industries may be different. This needs to be analyzed in depth according to the conditions specific to different industries. This study did not consider such factors when investigating the relationship between international technology transfer and the technical efficiency of Chinese HTM. This will be explored in future research.

\section{Data Availability}

The data of this study are obtained from China Statistics Yearbook on High Technology Industry, China Statistical Yearbook on Environment, and China Industry Statistics Yearbook. The data can be downloaded from the National Bureau of Statistics website.

\section{Conflicts of Interest}

The authors declare that there are no conflicts of interest regarding the publication of this paper.

\section{Acknowledgments}

The authors gratefully acknowledge the funding support from the Project of Humanities and Social Sciences of Ministry of Education of China (18YJC630131).

\section{References}

[1] Y. Miao, J. Song, K. Lee, and C. Jin, “Technological catch-up by east Asian firms: trends, issues, and future research agenda," Asia Pacific Journal of Management, vol. 35, no. 3, pp. 639-669, 2018.

[2] Y.-P. Lyu, H.-L. Lin, C.-C. Ho, and C.-H. Yang, "Assembly trade and technological catch-up: evidence from electronics firms in China," Journal of Asian Economics, vol. 62, pp. 65-77, 2019.

[3] X. Gao, "Approaching the technological innovation frontier: evidence from Chinese SOEs," Industry and Innovation, vol. 26, no. 1, pp. 100-120, 2019.

[4] L. Liu and X. Liu, "Indigenous R\&D technology import and domestic technological content of the manufacturing industry," Science Research Management, vol. 39, no. 8, pp. 34-42, 2018.

[5] C. H. Kwan, "The China-US trade war: deep-rooted causes, shifting focus and uncertain prospects," Asian Economic Policy Review, vol. 15, no. 1, pp. 55-72, 2020.

[6] J. Bonnitcha, "Investment wars: contestation and confusion in debate about investment liberalization," Journal of International Economic Law, vol. 22, no. 4, pp. 629-654, 2019.

[7] V. Vanchan, R. Mulhall, and J. Bryson, "Repatriation or reshoring of manufacturing to the U.S. And UK: dynamics and global production networks or from here to there and back again," Growth and Change, vol. 49, no. 1, pp. 97-121, 2018.

[8] Q. Xu, Y. Li, and H. Wu, "Market mechanism or non-market mechanism, which kind of technology transfer is benefit to innovation capability," Journal of Industrial Engineering and Engineering Management, vol. 34, no. 4, pp. 196-206, 2020.

[9] S. Awate, M. M. Larsen, and R. Mudambi, "Accessing vs sourcing knowledge: a comparative study of R\&D internationalization between emerging and advanced economy firms," Journal of International Business Studies, vol. 46, no. 1, pp. 63-86, 2015.

[10] L. Yu, H. Li, Z. Wang, and Y. Duan, "Technology imports and self-innovation in the context of innovation quality," International Journal of Production Economics, vol. 214, pp. 44-52, 2019.

[11] M. Andersson and T.-A. Stone, "Global sourcing and technical efficiency-a firm-level study on the Ict industry in Sweden," Journal of Business Economics and Management, vol. 18, no. 5, pp. 877-896, 2017.

[12] H. Belitz and F. Mölders, "International knowledge spillovers through high-tech imports and R\&D of foreign-owned firms," The Journal of International Trade \& Economic Development, vol. 25, no. 4, pp. 590-613, 2016.

[13] S. R. Suyanto, "Foreign direct investment spillovers and technical efficiency in the Indonesian pharmaceutical sector: firm level evidence," Applied Economics, vol. 45, no. 3, pp. 383-395, 2013.

[14] B. H. Suyanto, H. Bloch, and R. A. Salim, "Foreign direct investment spillovers and productivity growth in Indonesian garment and electronics manufacturing," Journal of Development Studies, vol. 48, no. 10, pp. 1397-1411, 2012.

[15] D. W. Sari, N. A. Khalifah, and S. Suyanto, "The spillover effects of foreign direct investment on the firms' productivity performances," Journal of Productivity Analysis, vol. 46, no. 23, pp. 199-233, 2016.

[16] B. A. Demena and S. K. Afesorgbor, "The effect of FDI on environmental emissions: evidence from a meta-analysis," Energy Policy, vol. 138, Article ID 111192, 2020.

[17] K. Laursen and A. Salter, "Open for innovation: the role of openness in explaining innovation performance among U.K. manufacturing firms," Strategic Management Journal, vol. 27, no. 2, pp. 131-150, 2006.

[18] H. Choi, "The social construction of imported technologies: reflections on the social history of technology in modern Korea," Technology and Culture, vol. 58, no. 4, pp. 905-920, 2017.

[19] J. Sun, L. P. Wu, and J. G. Qi, “The relationship between indigenous innovation and technology imports: substitution or complementarity," Studies in Science of Science, vol. 27, no. 1, pp. 133-138, 2009.

[20] D. Schiller, "The role of foreign and domestic firms in regional innovation systems of latecomer countries: empirical evidence from the electronics industry in the Pearl River Delta," Erdkunde, vol. 65, no. 1, pp. 25-42, 2011.

[21] R. Almeida and A. M. Fernandes, "Openness and technological innovations in developing countries: evidence from firm-level surveys," The Journal of Development Studies, vol. 44, no. 5, pp. 701-727, 2008.

[22] M. A. Cole, R. J. R. Elliott, and J. Zhang, "Growth, foreign direct investment, and the environment: evidence from Chinese cities," Journal of Regional Science, vol. 51, no. 1, pp. 121-138, 2011. 
[23] F. Peng and Y. P. Li, "Study of the relationship between technology transfer, indigenous R\&D and technical efficiency in high-tech industry," Science of Science and Management of S\&T.vol. 34, no. 5, pp. 44-52, 2013.

[24] A. Spithoven, B. Clarysse, and M. Knockaert, "Building absorptive capacity to organise inbound open innovation in traditional industries," Technovation, vol. 30, no. 2, pp. 130-141, 2010.

[25] L. Aldieri, V. Sena, and C. P. Vinci, "Domestic R\&D spillovers and absorptive capacity: some evidence for US, Europe and Japan," International Journal of Production Economics, vol. 198, pp. 38-49, 2018.

[26] M. Suyanto, R. A. Salim, and H. Bloch, "Does foreign direct investment lead to productivity spillovers? Firm level evidence from Indonesia," World Development, vol. 37, no. 12, pp. 1861-1876, 2009.

[27] R. Kneller and P. A. Stevens, "Frontier technology and absorptive capacity: evidence from OECD manufacturing industries," Oxford Bulletin of Economics and Statistics, vol. 68, no. 1, pp. 1-21, 2006.

[28] N.-S. Kwark and Y.-S. Shyn, "International R\&D spillovers revisited: human capital as an absorptive capacity for foreign technology," International Economic Journal, vol. 20, no. 2, pp. 179-196, 2006.

[29] M. Wang and M. C. S. Wong, "International R\&D transfer and technical efficiency: evidence from panel study using stochastic frontier analysis," World Development, vol. 40, no. 10, pp. 1982-1998, 2012.

[30] L.-b. Li, B.-l. Liu, W.-l. Liu, and Y.-H. Chiu, "Efficiency evaluation of the regional high-tech industry in China: a new framework based on meta-frontier dynamic DEA analysis," Socio-Economic Planning Sciences, vol. 60, pp. 24-33, 2017.

[31] X. G. Zhao and W. Zhen, "The technical efficiency of China's wind power list enterprises: an estimation based on DEA method and micro-data," Renewable Energy, vol. 133, pp. 470-479, 2019.

[32] Z. L. Xiao and X. Y. Du, "Measurement and convergence in development performance of China's high-tech industry," Science Technology and Society, vol. 22, no. 2, pp. 212-235, 2017.

[33] L. Shao, X. Yu, and C. Feng, "Evaluating the eco-efficiency of China's industrial sectors: a two-stage network data envelopment analysis," Journal of Environmental Management, vol. 247, pp. 551-560, 2019.

[34] Q. Wang and F. Y. Zhang, "The effects of trade openness on decoupling carbon emissions from economic growth-evidence from 182 countries," Journal of Cleaner Production, vol. 279, Article ID 123838, 2021.

[35] F. Chen, C. Wu, and W. Yang, "A new approach for the cooperation between academia and industry: an empirical analysis of the triple helix in East China," Science, Technology and Society, vol. 21, no. 2, pp. 181-204, 2016.

[36] D. Li, R. Hou, and Q. Sun, "The business performance evaluation index method for the high-tech enterprises based on the DEA model," Journal of Intelligent \& Fuzzy Systems, vol. 38, no. 6, pp. 6853-6861, 2020.

[37] J. Wei, Y. Liu, S. Jiang, and Z. Zhang, "Does ownership heterogeneity matter in technological catch ups? Empirical evidence from Chinese SOEs and POEs," International Journal of Technology Management, vol. 72, no. 4, pp. 253$272,2016$.

[38] K. Cullinane, T.-F. Wang, D.-W. Song, and P. Ji, "The technical efficiency of container ports: comparing data envelopment analysis and stochastic frontier analysis,"
Transportation Research Part A: Policy and Practice, vol. 40, no. 4, pp. 354-374, 2006.

[39] L. Jiang, Y. Jiang, Z. Wu, D. Liao, and R. Xu, "The measurement of innovation efficiency of Chinese high-tech industry using data envelopment analysis," Acta Oeconomica, vol. 65, no. s2, pp. 101-113, 2015.

[40] R. B. Mo, H. Y. Huang, and L. Y. Yang, "An interval efficiency measurement in DEA when considering undesirable outputs," Complexity, vol. 2020, Article ID 7161628, 12 pages, 2020.

[41] N. Dutta and K. Narayanan, "Impact of environmental regulation on technical efficiency: A study of chemical industry in and around Mumbai," Science Technology and Society, vol. 16, no. 3, pp. 333-350, 2011.

[42] V. Le, X.-B. Vu, and S. Nghiem, "Technical efficiency of small and medium manufacturing firms in Vietnam: a stochastic meta-frontier analysis," Economic Analysis and Policy, vol. 59, pp. 84-91, 2018.

[43] B. D. Suatmi, H. Bloch, and R. Salim, "Trade liberalization and technical efficiency in the Indonesian chemicals industry," Applied Economics, vol. 49, no. 44, pp. 4428-4439, 2017.

[44] S. Yu and H. Lu, "An integrated model of water resources optimization allocation based on projection pursuit model grey wolf optimization method in a transboundary river basin," Journal of Hydrology, vol. 559, pp. 156-165, 2018.

[45] A. Herrero, A. Jimenez, and S. Bayraktar, "Hybrid unsupervised exploratory plots: a case study of analysing foreign direct investment," Complexity, vol. 2019, Article ID 6271017, 14 pages, 2019.

[46] T. C. Li, L. Liang, and D. R. Han, "Research on the efficiency of green technology innovation in China's provincial high-end manufacturing industry based on the RAGA-PP-SFA model," Mathematical Problems in Engineering, vol. 2018, Article ID 9463707, 13 pages, 2018.

[47] Q. Wang and L. Zhan, "Assessing the sustainability of the shale gas industry by combining DPSIRM model and RAGAPP techniques: an empirical analysis of Sichuan and Chongqing, China," Energy, vol. 176, pp. 353-364, 2019.

[48] G. E. Battese and T. J. Coelli, "A model for technical inefficiency effects in a stochastic frontier production function for panel data," Empirical Economics, vol. 20, no. 2, pp. 325-332, 1995.

[49] J. Sarkis and J. J. Cordeiro, "Ecological modernization in the electrical utility industry: an application of a bads-goods DEA model of ecological and technical efficiency," European Journal of Operational Research, vol. 219, no. 2, pp. 386-395, 2012.

[50] D. Borozan, "Technical and total factor energy efficiency of European regions: a two-stage approach," Energy, vol. 152, pp. 521-532, 2018.

[51] H. Xie, M. Shen, and C. Wei, "Technical efficiency, shadow price and substitutability of Chinese industrial SO2 emissions: a parametric approach," Journal of Cleaner Production, vol. 112, pp. 1386-1394, 2016.

[52] X. Chen, Z. Liu, and Q. Zhu, "Performance evaluation of China's high-tech innovation process: analysis based on the innovation value chain," Technovation, vol. 74-75, pp. 42-53, 2018.

[53] Q. Deng, S. Zhou, and F. Peng, "Measuring green innovation efficiency for China's high-tech manufacturing industry: a network DEA approach," Mathematical Problems in Engineering, vol. 2020, Article ID 8902416, 13 pages, 2020.

[54] R. S. Mao and H. Wei, "Ownership characteristics, technology intensity and FDI technical efficiency spillovers," Management World, vol. 10, pp. 31-42, 2007. 
[55] M. Li and S. C. Liu, "Human capital and international R\&D spillovers: an empirical research based on OFDI transmission mechanism," Studies in Science of Science, vol. 29, no. 3, pp. 373-381, 2011.

[56] Y. H. Chung, R. Färe, and S. Grosskopf, "Productivity and undesirable outputs: a directional distance function approach," Journal of Environmental Management, vol. 51, no. 3, pp. 229-240, 1997.

[57] R. Ramanathan, "An analysis of energy consumption and carbon dioxide emissions in countries of the Middle East and North Africa," Energy, vol. 30, no. 15, pp. 2831-2842, 2005.

[58] X. Lu, J. Pan, and Y. Chen, "Sustaining economic growth in China under energy and climate security constraints," China \& World Economy, vol. 14, no. 6, pp. 85-97, 2006.

[59] C. N. Wu and J. F. Zhong, "Has preferential tax policy for technology imports improved industrial innovation capacity? A quasi-natural experiment based on China's catalogue for technologies encouraged to import," Contemporary Finance \& Economics, vol. 9, pp. 101-113, 2020.

[60] X. D. Chen, "The historical change of technology import to industrial upgrading and innovation in the past 40 years of reform and opening-up," Nanjing Journal of Social Sciences, vol. 1, pp. 17-25, 2019.

[61] R. Wang, R. Wang, and X. He, "Technical efficiency estimation of China's environmental protection enterprises and its heterogeneity," Environmental Science and Pollution Research, vol. 27, no. 26, pp. 33161-33180, 2020.

[62] B. Lin and H. Long, "A stochastic frontier analysis of energy efficiency of China's chemical industry," Journal of Cleaner Production, vol. 87, pp. 235-244, 2015. 